\title{
FRONTEIRAS, TRAJETÓRIAS E EXPERIÊNCIAS DE RUPTURAS*
}

\author{
LUCETTE LABACHE ${ }^{* *}$ \\ Monique de SAINT MARTin ${ }^{* * *}$
}

\begin{abstract}
RESUMO: Este texto analisa diferentes trajetórias individuais e familiares marcadas sobretudo por mobilidade social, profissional, geográfica e residencial e por descontinuidades. Membros dos diferentes grupos que constituem a sociedade francesa foram entrevistados por uma equipe de pesquisadores entre 2004 e 2007 , com o objetivo de apreender como os indivíduos ou as famílias jogam com as fronteiras sociais e espaciais, deslocando-as, transpondo-as ou construindo-as de forma ativa. Os resultados mostram que as experiências de ruptura de fronteiras específicas, como a do diploma, por exemplo, muito valorizado por certos atores, contribui para desenvolver disposiçóes para ultrapassar as fronteiras sociais ou, pelo menos, para não naturalizá-las tanto, quando não mais, quanto as próprias mobilidades social ou profissional. As fronteiras espaciais (nacionais e de bairro, em particular) são frequentemente evocadas nas entrevistas. O fato de se percebê-las e de se jogar com elas está estreitamente vinculado às experiências, mais especificamente às de deslocamentos e rupturas.

Palavras-chave: Trajetórias. Fronteiras. Mobilidade. Experiência. França.
\end{abstract}

Tradução de Alain François, com revisão técnica de Monique de Saint Martin e Ana Maria F. Almeida.

** Pesquisadora na Maison des Sciences de l'Homme (Casa das Ciências do Homem), membro da equipe "Expériences éducatives et construction des frontières" (Experiências educativas e construção das fronteiras) no Centre d'Étude des Mouvements Sociaux (Centro de Estudo dos Movimentos Sociais) em Paris. E-mail: 1labache@free.fr

*** Diretora de estudos na École des Hautes Études en Sciences Sociales (Escola dos Altos Estudos em Ciências Sociais) e pesquisadora no Centre d'Étude des Mouvements Sociaux, em Paris. E-mail:stmartin@ehess.fr

Educ. Soc., Campinas, vol. 29, n. 103, p. 333-354, maio/ago. 2008

Disponível em <http://www.cedes.unicamp.br> 


\section{BORDERS, PATHS AND EXPERIENCES OF RUPTURE}

ABSTRACT: This paper analyzes different individual and family paths rather marked by social, professional, geographical and residential discontinuities. Members of the different groups that constitute French society were interviewed by a research team, between 2004 and 2007, to seize how families and individuals play with social and spatial borders, displace them, overstep them or construct them in their activities. Our results show that breaking given borders, as that of diploma, for instance, which is much valued by some actors, helps develop tendencies to overstep social borders or at least, not to naturalize them as much or even more than social or professional mobility itself. Spatial borders (most particularly country or district borders) are often mentioned in these interviews. The fact that they are perceived and played with is closely linked to such experiences of displacement and rupture.

Key words: Paths. Ruptures. Borders. Mobility. Experience. France.

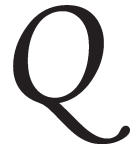

uando relatam suas trajetórias e as de suas famílias, mais especialmente quando estas são marcadas por uma mobilidade social, escolar, profissional, geográfica, residencial mais ou menos importante, os indivíduos também descrevem as fronteiras que tiveram de respeitar ou procuraram ultrapassar, contornar ou transgredir. ${ }^{1}$ De fato, nessas narrativas, as experiências de ruptura ou estabilização remetem a diferentes fronteiras sociais e simbólicas a serem ultrapassadas, ou então muito difíceis, quando não impossíveis de se transpor, as quais variam segundo as trajetórias. Às vezes, essas fronteiras sociais desempenham um papel de "muralha" que protege de um risco ou de uma desclassificação social (déclassement), outras vezes, representam um "fosso" a ser transposto em busca de escapatória. Cada fronteira atravessada marca as histórias familiais num sentido que tende a ser mais positivo, de promoção, para uns, ou mais negativo, de desclassificação social, para outros.

A noção de fronteira, que apenas foi conceituada recentemente nas ciências sociais, revela-se essencial para a compreensão dos grupos sociais. Por um lado, as fronteiras delimitam os contornos das categorias sociais (a participação desigual dos indivíduos na vida social) e, por outro, abrem espaços de troca e de encontro para que as classes se comuniquem 
entre si. De fato, como enfatizou Fredrik Barth (1995 [1969]), uma fronteira separa e possibilita trocas entre duas unidades que se reconhecem mutuamente como diferentes. Essa noção constitui uma ferramenta teórico-metodológica particularmente pertinente para refletir sobre as atuais formas múltiplas de manutenção e recomposição da distância entre os diferentes grupos sociais e entre os indivíduos nas sociedades afetadas por processos mais ou menos fortes de recomposição do social.

A demarcação de fronteiras sociais diz respeito a operaçôes tanto morais e cognitivas, quanto práticas e políticas (Tilly, 2004; Lamont, 2002; Lamont \& Molnar, 2002). As fronteiras separam o "nós" do "eles" e interrompem, circunscrevem ou produzem segregações na distribuição de populações ou de atividades dentro das sociedades. Essas fronteiras não são dadas, constroem-se, ultrapassam-se e desconstroem-se no tempo e com o tempo. Enquanto algumas já antigas são freqüentemente estabilizadas, outras, mais recentes, podem ser mais flexíveis e são mais freqüentemente questionadas. Entretanto, as fronteiras mais antigas também podem ser abolidas. Enfim, todo processo definidor de fronteiras sociais é o desfecho das lutas e conflitos pela classificação social (classement) e contra a desclassificação (déclassement) (Bourdieu, 1979).

Os modos de percepção e os processos de construção ou transgressão das fronteiras parecem fortemente vinculados às trajetórias coletivas (familiais ou geracionais) e individuais, assim como às histórias dos diferentes grupos de pertencimento. De fato, constituídos segundo a classe, o gênero, a nacionalidade, ou a origem, esses grupos vivenciam mais ou menos, segundo os casos, processos dinâmicos (diferentes formas de mobilidade, rupturas e recomposições). Embora os modos de percepção e os processos de construção e de transgressão de fronteiras dependam muito das condições estruturantes prévias, eles podem também se dever, em alguns casos, em grande parte, a disposições dos atores, experiências educativas, acontecimentos desencadeadores pouco "previsíveis" e aos contextos variáveis nos quais os atores se inscrevem. No contexto social atual, marcado por uma tendência à dissolução dos vínculos coletivos, pelo "fracionamento" relativo das classes sociais (que, freqüentemente, não são mais discernidas na sua forma "clássica”) e pelas mudanças qualitativas na noção e no papel do Estado, os efeitos das "contingências" e das "descontinuidades" variáveis das trajetórias são provavelmente mais visíveis e mais fortes do que algumas décadas atrás. 
Buscando apreender esses processos de construção, de inculcação e de enfraquecimento de fronteiras sociais hierarquizadas, uma equipe de pesquisadores realizou uma pesquisa, entre 2004 e 2007, nos diferentes grupos que constituem a sociedade francesa; ela se apóia principalmente num conjunto de 63 entrevistas aprofundadas e às vezes repetidas em 28 famílias (38 pais e 25 jovens de 12 a 21 anos), em Paris, em 3 cidades de tamanho médio nos subúrbios parisienses (Gennevilliers, Noisy le Grand e Sarcelles) e em 2 cidades de província: Estrasburgo e le Havre. ${ }^{2}$ Essas entrevistas enfocaram principalmente as histórias familiais e individuais, a percepção das fronteiras sociais, espaciais, temporais e de gênero, as experiências educativas apreendidas por meio da educação familiar recebida e da educação familiar dada. Ao observar a produção, a reprodução, o reforço ou o enfraquecimento das fronteiras pelos membros de cada um desses grupos, essa pesquisa busca contribuir para um estudo comparativo das classes sociais nas várias sociedades contemporâneas (França, Romênia, Suécia, Brasil), dando uma importância central à minúcia do cotidiano e à educação fora do sistema escolar, especialmente no âmago da família e de associações, sem, entretanto, ignorar a escola.

Como membros de diferentes grupos com trajetórias diferentes, mais em ascensão ou em declínio, com mais ou menos rupturas, situam-se em favor da manutenção ou da mudança de fronteiras, mais particularmente quando estas são sociais e espaciais? Como jogam com essas fronteiras, deslocam-nas, transpóem-nas ou constroem-nas em sua atividade e no decorrer de suas trajetórias?

\section{Rupturas de trajetórias e deslocamento de fronteiras}

Embora os processos de construção ou de tentativa de abolição de fronteiras possam ser apreendidos na escala de um grupo (associação, família) que tem interações freqüentes, também podem ser apreendidos em escala individual, ao analisar trajetórias marcadas por mais ou menos rupturas. Enquanto as trajetórias caracterizadas por um enraizamento num lugar e uma acomodação numa posição estabelecida (no sentido de Elias \& Scotson, 1965) podem levar a reforçar a consciência do "nós", a construir fronteiras nítidas para demarcar a separação dos outros grupos e a fixá-las, as trajetórias marcadas por rupturas e descontinuidades (fracasso escolar, divórcio, migração forçada de um país para outro, perda 
do emprego, sucessão de empregos precários), freqüentes nas famílias entrevistadas, em particular nas classes populares e médias, poderiam muito bem, como veremos, incitar à transgressão das fronteiras.

As pessoas entrevistadas na França tiveram experiências diversas de mobilidade geográfica. De fato, mesmo se ninguém mais mora onde nasceu, alguns continuam perto dos seus lugares de origem, enquanto outros percorreram grandes distâncias e o vínculo com os lugares de origem está frouxo, quando não completamente rompido. A travessia de fronteiras geográficas, que são ao mesmo tempo políticas e sociais, fronteiras entre Estados e fronteiras entre classes sociais, inscreve-se em duraçôes mais longas que definem as trajetórias dessas pessoas. Em nosso estudo, duas séries de acontecimentos estiveram majoritariamente na origem de modificaçôes das fronteiras: a mobilidade socioprofissional e a migração (que também costuma implicar mudanças de ordem socioprofissional).

Analisaremos aqui quatro trajetórias familiais e individuais de membros de famílias das classes médias e intermediárias para ressaltar o jogo com as fronteiras sociais e espaciais em suas trajetórias. ${ }^{3}$ Umas têm um caráter bastante banal, outras são mais excepcionais, marcadas por rupturas mais ou menos fortes. Isto nos permitirá objetivar o vínculo entre as experiências de rupturas, as descontinuidades das trajetórias e as diferentes fronteiras sociais e simbólicas ultrapassadas ou impossíveis de se transpor, segundo as trajetórias.

\section{Trajetórias ascensionais às vezes despedaçadas}

O percurso de Florence tem um movimento ascensional e é marcado por descontinuidades. Ela e seu ex-marido provêm de meios populares pouco escolarizados, mas, hoje, pertencem às classes médias de Gennevilliers, cidade dos subúrbios parisienses onde moram essencialmente operários e funcionários, e onde eles são funcionários municipais. Entretanto, se a situação do ex-marido parece estável (é engenheiro municipal concursado), a de Florence é diferente. Divorciada, mãe de três filhos (duas filhas de 23 e 17 anos e um menino de 14 anos), ela mora sozinha com os dois filhos mais novos num prédio HLM. ${ }^{4}$ Com 47 anos, passou sua infância e adolescência na Bretanha e chegou à Gennevilliers com 21 anos, para afastar-se de sua família. Já atravessou 
longos períodos de incerteza quanto a seu futuro (contratos provisórios, trabalhos temporários, interrupções de vários anos no nascimento de cada um de seus filhos). Embora se possa considerar que sua posição é, hoje em dia, mais estável do que no passado, isto é recente (em 2004, era secretária de uma associação ligada à municipalidade e acabou sendo efetivada como agente administrativa após passar em um concurso). A trajetória de sua família e a sua própria permitem apreender modalidades de construção de fronteiras entre grupos sociais, mas também entre ela e os outros.

Embora a trajetória familiar tenha sido mais ascensional, não foi acompanhada, por enquanto, por progressos importantes em termos escolares. Os avôs de Florence não estudaram, os pais, muito pouco (CAP [Certificação de Aptidão Profissional]), e Florence, como seus irmãos, não passou no baccalauréat. Esse fracasso marcou-a profundamente e, como acabou restringindo suas escolhas para progredir na função pública, ela se estima muito penalizada. Ela dá um lugar primordial aos diplomas, e o fato de não ter obtido o seu criou, manifestamente, fronteiras na sua trajetória: primeiro no momento do fracasso no baccalauréat, depois quando da escolha de seu cônjuge, que tinha dois anos de estudos superiores depois do baccalauréat, o que a agradou e até mesmo fascinou, pois lhe permitia ter um diploma "por procuração”. A importância dada aos diplomas também está clara nas esperanças e nos projetos escolares e profissionais que ela tem para seus filhos. Embora boa aluna, sua filha mais velha, após um ano de estudos de psicologia na faculdade, decidiu reorientar-se e prestou uma Certificação de Aptidão Profissional de cabeleireira, e foi aprovada. Primeiro, Florence custou a aceitar que sua filha, que tem um "superpotencial", exerça uma profissão manual e não faça estudos longos, mas acabou conformando-se, por ter sido escolha dela.

Depois de se separar do marido, Florence começou a fazer teatro, o que lhe permitiu conhecer novas pessoas, escolher amigos e tomar consciência de que existe enquanto indivíduo, pois, até então, considerava-se apenas como mulher de seu marido ou mãe de seus filhos. Encorajada a fazer teatro e tendo aí um certo sucesso, enquanto vivia mal seus fracassos anteriores, sobretudo o do baccalauréat, foi incitada a questionar seu estatuto de mãe de família e a ultrapassar novas etapas na sua carreira profissional; agora, pensa em prestar outro concurso, de redator, o que deverá melhorar sua situação financeira. 
Florence que, por um lado, teve uma trajetória marcada por rupturas familiais, fracassos e sucessos, uma relativa mobilidade profissional, geográfica e depois residencial (mudou várias vezes em Gennevilliers), investimentos escolares e culturais importantes, e, por outro lado, manifesta uma forte "vontade de autonomia" (econômica, familiar, para com o marido etc.), conseguiu não se deixar impor fronteiras sociais fortes demais e também soube demarcar uma fronteira entre ela enquanto indivíduo e os outros. Para ela, a educação dos filhos é muito importante e o diploma é o meio "por excelência" que permite a transposição desejada das fronteiras sociais. Essa forte valorização do diploma é sempre relacionada (em seu discurso) com seu próprio fracasso escolar. Essa experiência de fracasso pode ser interpretada como uma ruptura (com relação à instituição escolar, às suas expectativas e, provavelmente, às de sua família etc.). E é justamente enquanto ruptura, ou enquanto inflexão, que essa experiência desempenha um papel importante nas disposições para transgredir fronteiras e, em particular, na maneira de propor aos seus filhos um mandato de transgressão (de "progresso").

Joëlle também teve um percurso marcado por certa mobilidade e por rupturas. Com 45 anos, mora sozinha com os três filhos (duas filhas de 19 e 15 anos e um filho de 12 anos), após dois casamentos e duas separações. Perdeu o pai quando tinha 7 anos e foi criada em parte por seus avôs; sua mãe, que vivia doente e teve dificuldades para assumir suas responsabilidades familiais, morreu quando ela tinha 17 anos.

Nascida numa cidade dos subúrbios parisienses, muito cedo, Joëlle quis sair de lá. Aos 22 anos, realizou seu "sonho" de instalar-se em Paris, onde mudou várias vezes de bairro e pôde encontrar um posto de faxineira num colégio, depois de um longo período de "bicos". Embora tenha consciência de sua condição social, que qualifica de "pobre" e equipara à de seus vizinhos que moram no mesmo prédio HLM, o fato de ter ultrapassado a fronteira do periférico (boulevard que separa Paris de seus subúrbios) e de poder viver no $X I^{e}$ arrondissement parece representar para ela uma ascensão social significativa. Joëlle está muito envolvida na vida de sua paróquia católica, mais particularmente nas ações de caridade, que lhe permitem ter contato com pessoas de meios sociais mais privilegiados. Esse empenho nas atividades da paróquia, que remonta a uma época (a de sua segunda separação) em que atravessava uma situação muito difícil, material e psicologicamente, parece lhe trazer um apoio importante. Ela insiste que é graças às pessoas encontradas no círculo 
paroquial que foi levada a prestar o concurso na municipalidade de $\mathrm{Pa}$ ris: "Sem eles, não saía dessa". Essas pessoas, além de desempenharem um papel importante na sua vida familiar, pois ajudam na escolaridade de seus filhos com contribuições materiais (para comprar material escolar, por exemplo), também lhe dão conselhos sobre a educação de seus filhos, em particular sobre a escolha dos estudos e das carreiras.

Joëlle dá muita importância à escolaridade de seus filhos e espera que possam ir mais longe do que ela. Não falta arrependimento quando evoca seus próprios fracassos escolares, os quais justifica, em grande parte, pelos problemas familiares enfrentados (em particular, o fato de ter sido mal orientada na sua escolaridade e de ter fracassado quando da obtenção de seu diploma de estudos profissionais). O desejo de ruptura com a situação atual exprime-se fortemente nas aspirações que tem para seus filhos. Ela parece bastante engajada na busca do que pode lhes permitir ultrapassar as fronteiras sociais que os separam das classes médias ou privilegiadas.

Ela tem ambições elevadas para seus filhos: Brittany, Lindsey e Kevin (a quem deu nomes de heroínas e heróis da televisão, muito pouco comuns na França e com consonância anglo-saxônica, para que possam ter "um diferencial"). Joëlle gostaria que tivessem "boas profissões", como professor, assistente social, médico. Para ela, êxito profissional é sinônimo de trabalhar num escritório. Quando era faxineira na casa de famílias privilegiadas ("burguesas"), sempre ouvia a expressão "Estou saindo, vou ao escritório", que passou a admirar. Não pára de repetir essa história aos seus filhos para incitá-los a iniciarem um processo de distanciamento do seu meio social.

As diferentes rupturas ocorridas (mudanças de casa, divórcio, dificuldades econômicas) provavelmente contribuíram para que Joëlle entrasse em contato com outras pessoas (os moradores "burgueses" do XIe arrondissement), outras instituições (a municipalidade de Paris, onde entrou concursada), outras redes (a paróquia católica etc.), as quais favoreceram sua predisposição a ultrapassar as fronteiras (e, em particular, a buscar que seus filhos as transponham).

A trajetória atual da sua filha mais velha, Brittany, parece ir nesse sentido. De fato, ela sente ter uma dívida simbólica para com seu padrinho social, que a sustentou durante sua escolaridade e ajudou sua família. Ela renunciou aos estudos de sociologia e, seguindo os conselhos desse 
padrinho que a tutelava, iniciou estudos de direito. Atualmente no quarto ano de graduação, ela explica: "Gostaria de ter feito sociologia. Mas o senhor B. me disse que era mais sério fazer direito. Que poderia me abrir muitas carreiras. Como ele me ajudou muito, segui seus conselhos. Portanto, faço direito. Foi difícil segurar a barra. Mas como o senhor B. ajudou muito minha família também, segurei. Senão, teria sido uma vergonha. Bem, daqui a uns anos serei advogada”. Grata à sua mãe também, ela explica seu desejo de êxito como um meio de prestarlhe homenagem: "Minha mãe sofreu muito. Eu a vi sofrer. Sempre nos disse para não fazer como ela, para continuar estudando, já agora temos mais recursos do que ela teve nesta idade. Minha mãe trabalhou muito para nós. Portanto, meu presente para ela é ter êxito na escola. Fez muito por nós. Portanto, devo ter êxito nos meus estudos porque é importante para ela”.

O investimento nos estudos é particularmente importante para a filha de Joëlle e para a própria Joëlle, assim como era para Florence que, entretanto, conheceu uma decepção com a escolha de sua filha. Frente a experiências variáveis de mobilidade e de instabilidade familiar ou profissional, e até mesmo de rupturas, um certo desejo de ascensão, por vezes quebrado, mas também de enraizamento parece se desenvolver nessas duas famílias. Logo, a consolidação das redes de solidariedade constituídas territorialmente (o teatro para Florence, a paróquia para Joëlle) é uma meta importante por possibilitar "dispor de reservas de tipo relacional, cultural, econômico etc., que são os alicerces para a possibilidade de desenvolver estratégias individuais" (Castel \& Haroche, 2001, p. 30), e, portanto, encontrar apoios suscetíveis de trazer uma proteção, mas também uma incitação a afirmar sua autonomia e ultrapassar novas fronteiras.

\section{Uma trajetória movimentada}

Membro ativo de uma associação local multicultural, espaço de encontro e de ajuda mútua, em Noisy le Grand, e mãe de duas filhas, Charlotte, 51 anos quando da entrevista, tem uma trajetória particularmente movimentada. Entre todas as pessoas entrevistadas, é uma das que mais claramente exprimiu sua preocupação de não se deixar impor fronteiras sociais rígidas e, por sinal, se apresenta como alguém que não 
coloca "barreiras" entre ela e os outros, que é "contra o machismo, a excisão e escravidão de crianças".

Não sem um certo orgulho, conta que no começo de sua carreira profissional conseguiu fazer com que as funcionárias do banco onde trabalhava pudessem deixar de usar as roupas que eram obrigadas a usar. E continua explicando:

\begin{abstract}
"As pessoas chegam até mim porque não tenho barreiras. Vou lhe dar um exemplo: muita gente trabalha tarde, eu fazia isto em 2001, 2002, quando não queria voltar para casa, e aí chegavam as faxineiras africanas, na sala, e a gente se falava, eu perguntava como iam, e assim dava-lhes coisas. Depois a gente se tratava por 'tu', conhecia os nomes umas das outras, coisas que não se fazem, porque trabalho na direção geral de l'ANPE, ${ }^{5}$ e apenas 'graúdos' trabalham na direção geral, então tem coisas que não se fazem, sabe (...).

Nas Arcades (em Noisy le Grand) a gente vê essa mistura de culturas, e tudo aconteceu muito rapidamente ao mesmo tempo, começamos a ter contato com pessoas de todos os continentes, jovens, pessoas que não são muito escutadas por seus pais, e nós [seu novo companheiro e ela] adotamos, entre aspas, com o acordo de seus pais, obviamente, uma jovem cabo-verdense, a que mora com o ucraniano, vamos ao país dela daqui a três semanas, e decidimos abandonar esse meio tão inapropriado à nossa necessidade de troca”.
\end{abstract}

A curiosidade de Charlotte e até mesmo sua vontade de ser próxima aos outros, de ajudá-los, se deve, em parte, provavelmente, a suas experiências muitas vezes difíceis e também às "feridas" morais que recebeu no decorrer de sua trajetória dentro ou fora do âmbito familiar. Alguns acontecimentos foram particularmente marcantes nessa trajetória e contribuíram para traçar fronteiras temporais. Assim, a experiência que teve, com 18 anos, logo depois do baccalauréat, quando, após o falecimento de seu pai, teve de vender enciclopédias de porta em porta com sua mãe, provavelmente contribuiu para despertar sua "curiosidade para com o gênero humano" e sua "vontade de ajudar".

A trajetória de Charlotte é marcada por uma mobilidade geográfica muito grande: nascida em 1955 no Marrocos, ela viveu até os 7 anos "no coração de Argel”. Sua família voltou à França em 1963; seu pai trabalhava na polícia (comandante de brigada dos efetivos de combate) e a família mudou muitas vezes, indo de Langres, na Haute-Marne, para Dijon, Vesoul, Saint-Cloud e, de lá, como seu pai estava morrendo, para um vilarejo, perto de Bourg-en-Bresse. Quando se casou, em 1975, Charlotte foi para Belfort, depois para Besançon, onde nasceram suas 
duas filhas e, em seguida, para Cahors, onde morou por 12 anos e meio; acabou voltando para a região parisiense, na Seine et Marne, foi para perto de Salon de Provence e voltou novamente para a região parisiense, em Noisy le Grand.

Sua mobilidade profissional foi também muito elevada. Depois de ter vendido enciclopédias com a mãe, tornou-se recepcionista, em seguida corretora num banco durante quatro anos, vendedora de produtos de beleza e dietéticos, agente imobiliária durante mais de um ano em Cahors e, em seguida "o que chamam de 'preparador mental' para pilotos de uma fábrica de moto", o que a levava a mudar freqüentemente de empresa para acompanhar os pilotos. Hoje em dia, é executiva na ANPE de Noisy le Grand.

Mais ainda que a mobilidade geográfica ou profissional, o que chama a atenção no relato de Charlotte é uma mescla de experiências de situações freqüentemente extremas e de violência (estupros, tentativa de suicídio, situação de tensão dramática com seu ex-marido, problemas de saúde muito graves), com a narração de um dia comum em que evoca uma vida de família sossegada em casa: atividades domésticas, levar as duas filhas à escola, bate-papo no caminho com vizinhos, chá com as filhas na volta da escola, conversas com elas sobre os acontecimentos do dia.

A recusa das barreiras, a rejeição da naturalização das diferentes fronteiras sociais e das fronteiras de gênero exprimidas de modo eloqüente por Charlotte não podem ser explicadas de modo um tanto reducionista, tomando apenas em conta sua educação mais burguesa ou, ainda, sua forte mobilidade. É toda sua trajetória, apresentada aqui de modo esquemático, que se deve levar em conta, na sua complexidade, com as numerosas experiências de rupturas, geralmente doloridas, que evoca na forma de dramas, mas também com momentos de apego à vida familiar, com suas regras e seus ritos, se quisermos compreender como Charlotte pode, segundo as circunstâncias, manter intactas várias fronteiras de gênero, entre grupos sociais ou étnicos diferentes, ou simbólicas, ou então ativá-las mais ou menos fortemente e transgredi-las.

\section{Como reconstruir uma posição "perdida"}

A família de Rajini e Rajendra oferece um exemplo de trajetórias familiar e individual marcadas por rupturas e pela perda de status social, que não é, entretanto, vivida como inexorável. Elementos de 
descontinuidade marcaram as trajetórias sociais desses pais de três filhos. Originários do Sri-Lanka, Rajini e seu marido Rajendra obtiveram na França o estatuto de refugiados políticos; sua "inserção" na França pôde ocorrer parcialmente graças ao apoio de associaçôes e, em parte, graças à sua inscrição numa rede de solidariedade cingalesa na qual se conheceram.

Rajini e Rajendra vêm de famílias privilegiadas. Ela era bióloga, filha de médico, com diplomas de estudos superiores realizados em Sri Lanka e na Inglaterra, e ele, professor universitário depois de estudos superiores em Oxford; ambos moravam em "bairros chiques" em Sri Lanka. Desde sua chegada na França, Rajendra teve um percurso profissional descontínuo e exerceu várias atividades: primeiro, foi operário e almoxarife, em seguida, trabalhou em restaurantes e também teve uma experiência fracassada de dono de uma pequena agência de turismo. Ele distingue vários períodos na sua trajetória que analisa assim:

"Digamos que tive várias vidas. Uma vida de filho de família mimado. Uma vida de estudante que não passava necessidades. Em seguida, uma vida acadêmica com um futuro que não se realizou... o momento das desilusões... Depois, uma vida à deriva, sem documentos, sem estatuto, sem muitas coisas. Atualmente, nem sei como dizer, uma vida de suburbano sem nada demais. Bem, acredito que terei outra vida porque pedi a nacionalidade francesa. E isto vai mudar muito minha visão das coisas. Poderei votar, fazer coisas assim".

Apesar de várias tentativas, Rajini nunca conseguiu inserir-se profissionalmente enquanto bióloga, na França. Se, graças à reconversão profissional de Rajendra, a família parece, no momento, não enfrentar dificuldades econômicas fortes, seu nível de vida está longe de ser comparável ao que conheceu em seu país de origem. Rajendra é co-gerente de um pequeno restaurante do bairro indiano em Paris; dona de casa, Rajini se dedica à educação de seus três filhos, cuja escolaridade ela acompanha de perto, a atividades associativas e, ocasionalmente, a trabalhos de tradução de inglês.

Atualmente, de classe média baixa, essa família é dona, já a uns dez anos, de seu apartamento num bairro popular, classificado como área urbana "sensível" e desqualificado por uma imagem muito deteriorada, Le Pavé Neuf, na cidade de Noisy le Grand. As formas de instabilidade que vivenciou se devem a um percurso familiar de mobilidade 
social negativa mais do que a seus recursos materiais atuais e às defasagens, vividas com mal-estar, entre seus recursos socioculturais e a posição ocupada na sociedade francesa.

O modo atormentado como a instabilidade de sua posição "de baixo estatuto social" é vivida por Rajini se traduz na percepção negativa que exprime para com o bairro do Pavé Neuf. Por sua atitude de evitar a vizinhança, ela parece buscar demarcar a fronteira que a separa de sua família. Os filhos (dois dos quais são adolescentes) não têm o direito de passear sozinhos, seus amigos nunca são recebidos no domicílio familiar e, ao falar de sua filha mais velha, ela observa: "Suas amigas ligam para ela, mas não vêm em casa. Não quero muito... não quero ter que lidar com os pais delas". Ao conferir uma importância central ao controle de seus filhos e ao monitoramento de sua escolaridade, ela procura distanciar-se das famílias de seu bairro que não têm as mesmas preocupações.

"Por exemplo, quando houve as manifestações, os incêndios do ano passado (outono de 2005), a gente pensou: é preciso proteger nossos filhos ainda mais, ser ainda mais vigilantes... sobretudo, nós, as mães. Mas certas pessoas não concordavam porque diziam que não se pode vigiar os jovens o dia todo, que não estávamos mais nos anos 50. Aí, já não concordo, porque os pais não querem fazer seu trabalho. Portanto, isto criou dois campos: os que queriam mais severidade e os que diziam que não valia a pena. Neste caso, não posso lidar com pessoas assim".

O mal-estar de Rajini para com sua posição instável ou com certas famílias do bairro, assim como o desejo muito forte de superação das fronteiras sociais que, atualmente, rodeiam a família se exprimem no seu forte desejo de integração na sociedade francesa. Este se reflete, por exemplo, na escolha de nomes franceses para seus filhos, na sua preocupação em aprender a fazer e preparar regularmente comida francesa para acostumá-los e, ainda, nas aspirações profissionais que tem para eles "Quero que façam estudos brilhantes, com nível de engenheiro ou doutor". O futuro dos filhos é cogitado como uma ruptura radical com sua situação. Deverá a filha mais velha, Laetitia, brilhante aluna, cumprir um papel de "reparação" e aderir ao projeto de seu pai, que gostaria que entrasse numa grande école (escola de elite) como a Politécnica ou a Escola Nacional de Administração? De fato, este estima que o selo grande école é o mais seguro, pois abre mais portas e 
também permite a integração de toda a família na sociedade francesa, graças aos empregos prestigiosos aos quais dá acesso.

\section{As fronteiras espaciais}

Sejam elas marcadas por fortes descontinuidades e rupturas, como as de Rajini e Rajendra ou Charlotte, ou por rupturas mais fracas e uma forma de continuidade, como as de Florence ou Joëlle, as trajetórias inscrevem-se num espaço em que podem ocorrer migraçóes, mais ou menos antigas, entre países, regiōes ou cidades, ou ainda mudanças de bairros numa mesma cidade. Esse espaço é atravessado por fronteiras geográficas, jurídicas, sociais e simbólicas que separam ou unem; podem ser fronteiras continentais, nacionais, regionais, de bairro ou, mais simplesmente, fronteiras que separam o lugar de residência de outros lugares próximos, ou os trajetos cotidianos. Essas fronteiras no espaço são, provavelmente, as mais visíveis ou, pelo menos, as mais perceptíveis e as mais freqüentemente evocadas nas entrevistas; é nessas fronteiras vinculadas ao local de residência, à mudança de lugar, e nas fronteiras de bairro, relacionadas às trajetórias, que focalizaremos principalmente nossa atenção. $\mathrm{O}$ local onde se mora, o bairro, a cidade ou o vilarejo das origens marcam, de fato, fronteiras bastante fortes no relato de vários entrevistados.

\section{O lugar de residência e as mudanças}

De modo geral, o lugar de residência aparece, na França, cada vez mais como um marcador social; por sinal, Eric Maurin nota que "o mercado residencial talvez seja o lugar onde, hoje em dia, as novas linhas de fratura de nossa sociedade se revelam na sua mais cruel nitidez e, em particular, a ruptura entre as classes médias e as elites" (Maurin 2004, p. 12). As classificaçóes sociais passam por classificaçóes espaciais.

Se a trajetória foi mais contínua, regular ou então mais marcada por descontinuidades ou rupturas, o próprio local onde se mora (casa ou apartamento) poderá delimitar uma fronteira mais ou menos forte entre o individuo, o nós (a família) e os outros. Pode ser, por exemplo, que aqueles cuja trajetória foi marcada por migrações ou por muitos deslocamentos façam de sua residência um lugar relativamente menos fechado ou mais aberto que aqueles que se inscrevem na continuidade, com modalidades diferentes segundo as categorias sociais. 
Às vezes, o contexto também acaba mudando aqueles que se recusam a estabelecer fronteiras e que podem ser levados progressivamente a construir distâncias com relação a seus vizinhos ou a pessoas próximas.

As mudanças de lugar de residência, desejadas, buscadas ou sofridas, aguçam a percepção das fronteiras e podem incitar a transgredi-las. Para Joëlle, sair do "buraco", como designa pejorativamente a cidade de subúrbio de onde vem (Créteil), para instalar-se na capital significou a concretização de um sonho e um êxito social. Sua chegada em Paris, com 22 anos, marcou, para essa antiga suburbana, um corte com seu passado. Assim, ela visualiza um futuro "melhor" e uma possível via de ascensão social com relação a seu meio de origem e pôde relegar à condiçãao de passado todos os estereótipos de que sofreu quando era suburbana. Mas também tem consciência de que são essencialmente "pobres" os que moram no mesmo conjunto HLM do XI arrondissement de Paris que ela e seus filhos: a comparação com os "burgueses" com os quais tem contato na paróquia e que, a seus olhos, exercem ofícios prestigiosos faz com que tenha consciência de seu estatuto econômico de desfavorecida.

Ir morar em Paris ou em seus subúrbios pode assim representar uma promoção social, constituir a realização de um sonho, mas nem por isso deixa de ser difícil, como, por exemplo, no caso de Florence, vinda de Bretanha com 21 anos. Uma fronteira pode, de fato, por um tempo, pelo menos, se estabelecer entre os provincianos, "os caipiras", e os parisienses, que nunca perdem uma oportunidade de lembrar à provinciana que essa fronteira existe.

Para Pauline e Bernard, morar no Pavé Neuf em Noisy e ser, enfim, locatários confiáveis representou um momento-chave em sua trajetória. Depois de ter sido preciso vender a sua casinha devido ao desemprego, o casal acumulou múltiplas experiências de vulnerabilidade. Nascida em Montreuil, cidade nos subúrbios parisienses, Pauline, 43 anos, é ajudante de enfermagem no hospital Hôtel-Dieu, em Paris. Já teve vários contratos precários: foi cozinheira num centro de acolhimento para crianças, vendedora numa loja de sapatos e demonstradora de diferentes produtos em supermercados. Uns doze anos atrás (1995), entrou na Assistance Publique-Hôpitaux de Paris como faxineira. Em 2001, seguiu uma formação para tornar-se ajudante de enfermagem e foi lotada no Hôtel-Dieu.

Nascido num subúrbio de Lille, Bernard, 45 anos, chegou à região parisiense em 1981, com 20 anos. Como sua mulher, teve experiências profissionais diversas: lavador de prato, ajudante de cozinha, pintor, 
ajudante de mecânico, operador de triagem nos Correios, motorista entregador e marceneiro. Desde 1999, e até hoje, trabalha na Assistance Publique-Hôpitaux de Paris como operário no hospital Saint-Louis.

Os dois se conheceram em 1991 e se juntaram no mesmo ano. Tiveram três filhos: Marie-Julie, 16 anos, Ariane, 12 anos e Paul, 10 anos. Instalados primeiro numa kitchenette do $X X^{e}$ arrondissement de $\mathrm{Pa}-$ ris, Pauline e Bernard se casaram em 1992 e decidiram comprar uma pequena casa em Nanterre. Devido à demissão de Bernard em 1994, as dívidas obrigaram o casal a vender a casa. Pais e filhos instalaram-se num apartamento de dois quartos num prédio HLM, em Noisy le Sec. Novamente, dificuldades financeiras levaram o casal a pedir ajuda à família. Os pais de Pauline os acolheram, mas em seguida o casal enfrentou outros tipos de problemas: alcoolismo de Bernard, que acabou indo morar num squat (casa invadida), e depressão de Pauline, que estava desempregada e foi morar num centro de acolhimento para mães e filhos, em Paris. Em seguida, ela ficou vários meses num quarto de hotel, sempre com os filhos. Entrou na Assistência Pública (uma assistente social tinha lhe aconselhado mandar seu currículo vitae para essa instituição) como temporária, começou trabalhando na lavanderia e depois como faxineira. Após sua efetivação, incitou Bernard a se candidatar para um emprego na Assistência Pública. Ele foi lotado no serviço de higiene e depois na manutenção. Mesmo após Pauline e Bernard conseguirem estabilizar sua situação profissional, as dívidas contratadas não lhes deixavam muito dinheiro, motivo pelo qual enfrentavam graves dificuldades para ter acesso a uma habitação. Começaram então a militar em associações de direito à habitação e apelaram para associações de caridade. No fim, foi a assistente social da Assistência Pública que encontrou sua habitação atual de três quartos no Pavé Neuf em Noisy, a qual, para eles, marca uma etapa importante.

De fato, depois das experiências de evicção de sua casa por causa de inadimplência, de vida em squats, na casa da família e num hotel, o casal vivenciou a obtenção desse apartamento de subúrbio, num bairro desfavorecido, como uma promoção social. E mais ainda porque essa mudança teve conseqüências positivas sobre a vida do casal: estabilização de sua união, saída da precariedade profissional, nova sociabilidade, dinamização de sua vida e, no plano psicológico, recuperação da autoconfiança e sentimentos de um desabrochar. Marie-Julie, sua filha adolescente, que guardou seqüelas da precariedade residencial passada, 
inseriu-se bem no bairro, apesar de ser mal-afamado: "Tenho pesadelos de que não tenho mais essa casa, de que não moro mais aqui no Pavé Neuf. $\mathrm{Na}$ realidade, tenho medo de mudar de casa de novo... Gosto deste bairro, mesmo se as pessoas falam muito mal dele. Aqui me sinto bem. Tenho muitas amigas. Conheço muita gente”.

Diferentemente, Rajendra e Rajini, embora proprietários do seu apartamento, desejam ir embora do Pavé Neuf, particularmente por causa de seus filhos que gostariam de ver crescer num lugar mais seguro e sossegado. O pai confessa seus temores de que os filhos trilhem o caminho das drogas ou sofram violências sexuais entre adolescentes.

"Estamos pensando em mudar. Quando os filhos são pequenos, a gente não percebe certas coisas. Agora, é verdade que tenho muito medo da droga, e depois do que vimos quando das manifestações contra o Contrato Primeiro Emprego (CPE), todas essas moças que também participavam, que quebravam lojas, que queimavam carros. Bem, não gostaria de ter de ir buscar minha filha na delegacia. Portanto, adolescentes, é preciso saber segurá-los. Como tenho duas filhas moças, também há os "tournantes" (estupros coletivos): é preciso protegê-las disto".

Embora atue numa associação para tentar mudar a imagem de seu bairro, Rajini também exprime essa esperança, ainda que de modo mais discreto: "O bairro do Pavé Neuf, é verdade, que não é grande coisa... tem má reputação... As pessoas têm medo de sair à noite (...). Moramos aqui, mas preferimos morar em outro lugar”.

As fronteiras nas trajetórias vinculadas ao espaço são muito imbricadas com a experiência individual de cada um. Experiências muito diferentes foram assim vivenciadas pelos casais Rajini-Rajendra e Bernard-Pauline, que moram no Pavé Neuf em Noisy le Grand: no primeiro caso, o lugar de residência é sinônimo de uma queda social (ocorrida em conseqüência de uma migração política), se comparado com o luxo em que moravam em Sri Lanka, antes de seu período migratório; no segundo, após vários anos de errância habitacional, aos quais se somaram dificuldades pessoais, o acesso a uma habitação num bairro desfavorecido é, pelo contrário, vivido de maneira decididamente positiva. Entretanto, ambos os casais, cujas trajetórias foram, segundo modalidades muito diferentes, marcadas por numerosas experiências de rupturas, manifestam mais ou menos fortemente, segundo os momentos de sua vida, uma disposição para ativar e deslocar fronteiras. 


\section{As fronteiras na cidade: $o$ bairro}

$\mathrm{Na}$ realidade, como lembra Marco Oberti (2007, p. 268), a homogeneidade social é mais forte nos bairros burgueses, cuja seletividade residencial se reforçou no decorrer dos últimos anos, do que nos bairros populares, de habitações sociais. $\mathrm{O}$ pertencimento ao meio burguês passa por uma forma pronunciada de segregação urbana, cujos componentes incluem bairros chiques e vontade de estar "entre-si". As classes privilegiadas têm recursos (econômicos, informativos, relacionais...) para escolher o lugar onde querem residir, onde podem isolar-se e manter-se "entre si". "O caráter muito restrito do espaço residencial das classes altas mostra bem que, embora as coerções econômicas pesem pouco sobre elas, as coerções sociais, em compensação, são muito fortes" (Pinçon \& Pinçon-Charlot, 1989, p. 30).

Nas entrevistas feitas durante nossa pesquisa com membros da burguesia que moram em Estrasburgo, as vantagens práticas ("é perto do centro da cidade", "podemos fazer tudo de bicicleta", "a escola das crianças fica ao lado") ou a graça do lugar são sempre evocados. A extrema concentração espacial da burguesia, das classes superiores favorece os encontros, imprevistos ou deliberados, e pode facilitar a inserção social num ambiente social próximo ao seu. A importância do "entre-si" burguês evidencia-se em expressões como "os bairros onde se deve morar", "a escola onde se deve ir", "a boa paróquia". As famílias das classes privilegiadas evoluem em espaços residenciais relativamente limitados. Em Estrasburgo, os "bairros chiques" situam-se principalmente nos bairros da Orangerie (perto das instituições européias), do Conseil des Quinze e dos Contades, no bairro Robertsau e no centro da cidade. Graças a fronteiras relativamente "visíveis" (parques, ruas, prédios...), é fácil localizar de modo bastante exato os "bairros chiques". A continuidade habitacional desses bairros favorecidos permite atar relações pelas quais se opera uma inserção social em profundidade.

Por outro lado, a escolha das escolas evidencia que essas famílias, que moram em bairros "chiques", têm uma percepção aguçada das fronteiras e dos muitos pontos de referência que lhes permitem distinguir lugares e escolas onde não mandar seus filhos dos estabelecimentos escolares geralmente reputados, que parecem lhes convir plenamente. Quando as escolas próximas não as agradam, essas famílias podem escolher colégios públicos com opções específicas (russo, aulas de música) para evitar 
a carta escolar, que, até hoje, determinava o estabelecimento escolar que as crianças devem freqüentar em função de onde moram; ou então estabelecimentos privados: o custo financeiro não é um problema para elas, mesmo quando vários filhos freqüentam esses estabelecimentos. De fato, dispõem dos recursos (relacionais, econômicos...) necessários para escolher uma escola que garanta um espaço de relaçôes bastante uniforme e o mínimo de diversidade na homogeneidade social.

$\mathrm{Na}$ burguesia, as famílias valorizam seu pertencimento a tal ou tal bairro, do qual não relutam falar: suas escolhas costumam recair em bairros reputados e calmos. Morar num bairro chique constitui um estigma positivo, que valoriza o lugar de residência e o próprio morador.

Nos meios populares, e numa fração das classes médias ou intermediárias, o mesmo não se dá. O bairro é antes "sofrido", ou escolhido por não ter outro melhor. Por falta de meios financeiros, geralmente, os entrevistados são obrigados a permanecer em bairros que nem sempre os agradam e onde se vêem "bloqueados". Às vezes, evocam seu lugar de habitação de maneira negativa e costumam aspirar a abandonar esse bairro.

A construção de fronteiras também se percebe nas falas dos pais sobre os amigos de seus filhos e no que empreendem para protegê-los. Assim, em várias famílias que moram num bairro popular, os pais evocam os problemas de violência, de delinqüência, de droga e as regras de educação que elaboram para proteger seus filhos das más amizades, como, por exemplo, não deixá-los brincar sozinhos em baixo do prédio e controlar rigorosamente seus horários de volta.

Ser reconhecido como morador num bairro "violento" ou "perigoso" constitui um estigma mais negativo e pode desvalorizar o habitante. Entretanto, alguns indivíduos tentam ultrapassar essa categorização, imaginam um lugar de habitação mais sossegado e atuam de diferentes maneiras para mudar a imagem de seu bairro.

Em Noisy le Grand e, num grau menor, em Gennevilliers, as fronteiras entre diferentes bairros ou diferentes locais de habitação, que abrigam frações mais ou menos importantes de meios populares ou de classes intermediárias e médias e de originários de diferentes países, são perceptíveis e freqüentemente evocadas e comentadas nas entrevistas. No Pavé Neuf, em Noisy, a forte segregação de certas populações, umas das quais vive em encraves, é citada pelos responsáveis de associações como tendo efeitos sobre a escolaridade das crianças. 
Rajendra insurge-se contra a terminologia étnica empregada para designar seus filhos, assim como os dos outros "Indianos" que são chamados de "pounde", termo que, em tâmil, significa pessoa sem valor. Extraída de seu contexto de origem, a palavra é desprovida de todos os afetos a ela vinculados; desse modo, não provoca emoções particulares nos jovens que assim são chamados ou até reivindicam esse nome. Do mesmo modo, os filhos de vietnamitas, cambojanos o laosianos são designados pelo termo de "banana", percebido como insultante por seus pais, mas que eles não consideram necessariamente estigmatizante. Num movimento de apropriação, eles até o fizeram evoluir para "nanaba".

Diferentes fronteiras sociais e espaciais, quer sejam escolhidas ou sofridas, surgem como marcadores pertinentes na análise das trajetórias dos indivíduos. Elas constituem, portanto, um laudo de êxito, de perda de status social ou de manutenção de uma consciência de grupo. As trajetórias habitacionais que evidenciam as fronteiras mais imediatamente discerníveis mostram o impacto das migraçôes internacionais, dos deslocamentos em nível nacional, regional, no espaço de uma cidade ou de um bairro, na vida dos sujeitos. Este espaço é atravessado por fronteiras simbólicas que separam ou unem e são percebidas como prestigiosas para uns ou estigmatizantes para outros.

\section{Conclusão}

A análise esboçada aqui de algumas trajetórias de indivíduos de diferentes famílias, mais marcadas pela mobilidade e as descontinuidades, permitiu apreender as rupturas, a produção e a transgressão das fronteiras sociais. No momento de relatar sua trajetória, cada pessoa ou família aponta e enfatiza a importância de uma ou, às vezes, várias fronteiras mais do que de outras (o fato de ter desejado morar em Paris para Joëlle; a rejeição da escolha de um ramo profissional por sua filha, os diplomas e concursos ou ainda a separação com seu marido, para Florence; uma grande diversidade de fronteiras deslocadas, mas também, às vezes, aceitas, para Charlotte; o início em Sri-Lanka e sua chegada na França, o tempo anterior marcado pela nostalgia de uma vida confortável, mas perturbada pela guerra civil e o tempo presente, na França, sinônimo de queda social, as fronteiras de vizinhança 
e de bairro no Pavé Neuf, para Rajini e Rajendra; a chegada ao Pavé Neuf, após de múltiplas experiências penosas, para Pauline e Bernard).

Coloca-se, assim, a questão de saber se a experiência de certas rupturas de fronteiras específicas, que os atores avaliam positivamente, não contribui para desenvolver disposiçóes para ultrapassar as fronteiras sociais ou, pelo menos, para não naturalizá-las, ao menos tanto, quando não mais, quanto a mobilidade geográfica ou profissional em si. São as fronteiras vinculadas aos estudos e aos diplomas que os diferentes pais tentam geralmente ativar e deslocar ao encorajarem, inclusive nos grupos mais precários, seus filhos a investir nos estudos e a ter êxito. Tudo isso não exclui, às vezes, um sentimento de desconfiança para com essa escola que não corresponde à suas expectativas. As fronteiras espaciais (nacionais, de bairro), em particular, são muito freqüentemente evocadas e sua percepção, assim como o jogo com elas são estreitamente vinculados às experiências e, mais particularmente, às experiências de deslocamento e ruptura.

As fronteiras não são adquiridas. São práticas vivenciadas, construídas e reconstruídas na atividade, notadamente, no decorrer das experiências educativas e das experiências de ruptura. As fronteiras podem sempre ser questionadas; podem ser, senão transgredidas, pelo menos ativadas e deslocadas, e têm tanto mais chances de sê-lo quando os indivíduos vivenciaram trajetórias marcadas por descontinuidades importantes.

\section{Recebido em maio de 2008 e aprovado em junho de 2008.}

\section{Notas}

1. Fronteiras também podem ser apreendidas quando os indivíduos confrontam a educação que vêm dando a seus filhos com a que eles mesmos receberam.

2. Essa pesquisa foi realizada no Centre d'étude des mouvements sociaux (CEMS); o conjunto dos resultados do estudo deu lugar a um relatório final (Saint Martin \& Gheorghiu, 2007). As análises desenvolvidas, em particular no capítulo VI, constituem o ponto de partida deste artigo que se apóia também em análises elaboradas por outros autores do relatório nos demais capítulos. Cabe enfatizar e agradecer a contribuição dos outros membros da equipe do CEMs (Mihaï Dinu Gheorghiu, Pascale Gruson, Denis Merklen, Barbara Bauchat, Daniella Naves de Castro Rocha e Mariana Heredia) para as análises aqui propostas.

3. As entrevistas foram realizadas por Judit Vari (Florence), Lucette Labache (Joëlle e sua filha mais velha, Rajini e Rajendra, Pauline e Bernard) e Mihaï Dinu Gheorghiu (Charlotte). 
Fronteiras, trajetórias e experiências de rupturas

4. N. do T.: Literalmente, "habitaçôes com aluguel moderado", um tipo de habitação cujo aluguel é subsidiado pelo Estado.

5. N. do T.: Agence Nationale pour l'Emploi: Agência Nacional Para o Emprego, órgão governamental encarregado de ajudar os desempregados a reencontrar um emprego.

6. A cidade de Estrasburgo desenvolveu uma importante rede de ciclovias que facilita a vida dos ciclistas.

\section{Referências}

BARTH, F. Ethnic groups and boundaries. Bergen, Oslo: Universitetsforlaget, 1969. (Trad. francesa: BARTH, F. Les groupes ethniques et leurs frontières. In: Poutignat, P; Streiff-Fenart, J. (Dir.). Théories de l'ethnicité. Paris: PUF, 1995. p. 203-249).

BOURDIEU, P. La distinction: critique sociale du jugement. Paris: Minuit, 1979.

CASTEL, R.; HAROCHE, C. Propriété privée, propriété sociale, propriété de soi. Paris: Fayard, 2001.

ELIAS, N.; SCOTSON, J. Logiques de l'exclusion. Paris: Fayard, 1997. (Trad. da 1a. edição inglesa de 1965).

LAMONT, M. La dignité des travailleurs. Paris: Sciences Po, 2002.

LAMONT, M.; VIRÁG, M. The study of boundaries in the social sciences. Annual Review of Sociology, Palo Alto, n. 28, p. 167-195, 2002.

MAURIN, E. Le ghetto français: enquête sur le séparatisme social. Paris: Seuil, 2004.

OBERTI, M. L'école dans la ville: ségrégation - mixité - carte scolaire. Paris: Sciences Po, 2007.

PINÇON, M.; PINÇON-CHARLOT, M. Dans les beaux quartiers. Paris: Seuil, 1989.

SAINT MARTIN, M.; GHEORGHIU, M.D. (Coord.). Education et production des frontières sociales: familles, monde associatif et institutions scolaires. Paris: EHESS/CEMS, 2007. (Rapport final de recherche).

TILLY, C. Social boundary mechanism. Philosophy of Social Sciences, v. 34, n. 2, p. 211-236, jun. 2004. 